\title{
Seafarers' mental health in the COVID-19 era: lost at sea?
}

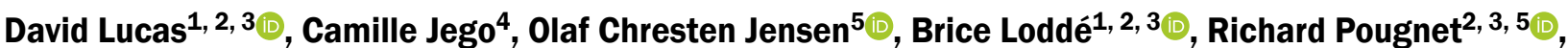 Jean-Dominique Dewitte ${ }^{2,3,5}$, Thierry Sauvage $^{3,6}$, Dominique Jegaden $^{3}(\mathbb{D}$}

\author{
${ }^{1}$ ORPHY Laboratory, University Brest, Brest, France \\ ${ }^{2}$ Occupational and Environmental Diseases Centre, Teaching Hospital, Brest, France \\ ${ }^{3}$ French Society of Maritime Medicine Brest, France \\ ${ }^{4}$ Psychology Unit for Seamen, Psychiatry Service Hospital, St. Nazaire, France \\ ${ }^{5}$ Centre of Maritime Health and Society, University of Southern Denmark, Esbjerg, Denmark \\ ${ }^{5}$ Laboratoire d'Etude et de Recherche en Sociologie (EA 3149), Université de Brest - Bretagne Occidentale, Brest, France \\ ${ }^{6}$ Seamen's Health Service, Ministry of Transport, Paris-La Defense, France
}

\begin{abstract}
Seafarers are exposed to several physical and psychosocial stressors. Recent studies highlighted specific disorders as fatigue, boredom and diseases as depression. Seafarers are also commonly exposed to post-traumatic stress disorder (piracy, accidents, threats). Coronavirus disease 2019 (COVID-19) impacts seafarers with an estimated 400,000 of whom are stranded on vessels around the world, with extended time on board, repatriation's difficulties and the financial concerns of the unexpectedly unemployed. International Maritime Organization has established the Seafarer Crisis Action Team to help them. In France, in last 10 months a dedicated call centre received 142 calls from 32 seafarers for psychological phone consultations mostly linked to this era. With the increase of duration of the COVID-19 crisis, psychological health care, repatriations and financial solutions are needed for seafarers.
\end{abstract}

(Int Marit Health 2021; 72, 2: 138-141)

Key words: maritime medicine, psychological impact, seafarers, COVID-19

\section{INTRODUCTION}

In recent decades, studies increased knowledge on occupational physical and psychological stressors exposure in seafarers. Some, like fatigue, boredom and social isolation are linked to social and technology modifications. Global economic growth is coupled with shipping trade and maritime technology has to respond to globalisation signals. Globalisation encouraged transactions of goods and service "just in time" in smaller packets. Maritime transport, shipping but also fishing is now directly impacted by worldwide globalisation. The International Maritime Organization has recently circulated communications on the coronavirus disease 2019 (COVID-19) pandemic risk for maritime workers with impact on goods transport, limitation of international travel opportunities. Objectives of this paper are to de- scribe seafarers' mental health and associated factors in a narrative review and in a second part to answer if in the COVID-19 era, additional damaging effects appeared.

\section{SEAFARERS' MENTAL HEALTH AND ASSOCIATED FACTORS}

Oldenburg et al. [1] recently published an article on stress and strain among seafarers considering their jobs on board. With a sample of 323 seafarers employed on 22 container ships, they conducted an interview-based study with a questionnaire addressing stressors among seafarers validated in a previous study [2]. Specific job-related factors such as sailing route, trip duration at sea, physical stressors (e.g. noise and seasickness) and psychosocial stressors (e.g. shift to new ship and social problems due to 
migration) were assessed. Nautical officers more frequently felt mentally stressed than the ratings, which the authors attributed to their higher maximum working hours and higher work-related demands. They also found that watchkeepers had significantly shorter sleeping periods than daytime workers (i.e. $5.5 \mathrm{~h}$ vs. $5.8 \mathrm{~h}$ ) and significantly lower scores for effectiveness of sleep, the overall average of which was $69.6 \%$ (odds ratio [OR] 0.48; 95\% confidence interval [Cl] $0.26-0.88$ ). In view of those findings, the authors proposed a possible relationship between chronic fatigue and human error during maritime disasters [1].

Fatigue is considered to be a major threat to maritime safety and mental health among seafarers, the youngest of whom have reported feeling overburdened by stress, especially due to fatigue and a lack of good social relationships and of control on board [3, 4]. On German-flagged merchant ships, individual stress levels were assessed in relation to 23 stress factors, most notably separation from family, pressure of time, long working hours, high temperatures in workplaces and lack of skills among subordinate crew members. By job type, officers complained more often than non-officers about high stress levels due to time constraints and administrative tasks [1]. In other work, a survey conducted in France with 74 seafarers employed on oceanographic vessels examined stress using the Karasek's demand-control model [5]. Among the respondents, 17\% had low job-related decision-making latitude, which indicates a high risk of stress, and 33\% showed mental stress on their overall health tests. A particular risk factor among officers was a backlog of administrative work while in port, which creates difficulty with organizing work efficiently [1].

Another aspect of occupational mental health among seafarers is boredom which occurs due to daily monotonousness combined with frustration [6]. That combination is common among seafarers, who generally experience the monotony of work on board at sea, particularly routine deck chores, time on watch and maintenance tasks. Such boredom at work is a source of stress and addiction, according to data in the literature, even if most studies on boredom among transport workers have been done in the air and road transport sectors [7-12]. In a recent exception, Jegaden et al. [13] interviewed 80 seafarers -40 officers, 40 crew members - and 63 office staff with three validated questionnaires: Boredom Proneness Scale (BPS), the Hospital Anxiety Depression Scale and the Job Content Questionnaire (JCQ). Between the two groups of seafarers, significant differences emerged for boredom disposition score $(p=0.02)$ and external stimulation score $(p=0.05)$. The results on the JCQ significantly differed in average sense of job demand and job control, whereas no difference surfaced for social support [13]. Compared with the officers, the crew had significantly low sense of job demand and job control, which ranked them in the passive workers category (51\%). By contrast, the percentage of active workers was significantly higher among officers (30\% vs. $5.1 \%$ ) [13]. Oldenburg and Jensen [14] found that insufficient opportunities for telecommunication were experienced as a work-related strain among seafarers assigned to worldwide destinations (OR 1.87, 95\% Cl 1.15-3.04) and crew members without children (OR 2.00, 95\% Cl 1.03-3.88). Moreover, in another interview-based study with 337 seafarers employed on Chinese-flagged ships, An et al. [15] found a significant, negative correlation between work performance and both work-family conflict $(p<0.05)$ and occupational stress $(p<0.05)$. In their logistic regression model, job satisfaction played a moderating role in the relationships between work-family conflict, job stress and work performance, and relationships between job stress, work-family conflict, work performance and satisfaction at work resembled ones in Siegrist's effort-reward imbalance model $[15,16]$.

At sea, less job demand can be expected to accompany a risk of boredom due to monotony and the repetitiveness of tasks. Many studies have confirmed the strong relationship between proneness to boredom and depression. Stress and strain among seafarers are related to greater job demands and management tasks during stays in port and during arrival and departure periods [17-19]. Iversen [20] found that from 1960 to $2009,5.9 \%$ of all reported deaths were due to suicide and $13.1 \%$ to illness.

Seafarers are also commonly exposed to post-traumatic stress disorder (PTSD). In interviews with 323 seafarers on German ships addressing severe mental stress or potentially traumatic events on board, $35.9 \%$ of seafarers reported experiencing major maritime disasters, threats or accidents, including piracy on board (17.0\%) and stowaways (39\%). Added to that, $83.6 \%$ of seafarers who had experienced disasters and $76.4 \%$ who had experienced piracy reported often unintentionally thinking about the events or dreaming about them. Experiences involving the threat of stowaways had particularly affected non-European seafarers. According to interviews at 12 shipping companies conducted in 2020 a total of 14 deaths had occurred in the past 3 years in the companies: 3 due to heart attack, 3 due to cancer, 3 due to accidents, 2 due to suicides and 3 due to unknown causes [21].

Today, as the International Maritime Organization (IMO) has declared on its website, the COVID-19 pandemic has put seafarers around the world at risk of another set of precarious situations, which may in turn affect their mental health. Travel restrictions have meant that they cannot leave their ships, be repatriated home or even receive urgent medical assistance. Other seafarers have seen their contracts unilaterally terminated or been quarantined on board their vessels for more than 14 days, all without pay. Numerous seafarers, 
their spouses and family members have contacted the IMO to share their concerns about a range of difficult situations caused by the COVID-19 pandemic. As some consolation, the theme for this year's World Mental Health Day is "Mental Health for All", which could be good news for seafarers, an oft-forgotten part of the workforce [22].

As COVID-19 continues to adversely impact seafarers, an estimated 400,000 of whom are stranded on vessels around the world, many working within the maritime industry have become increasingly concerned about the damaging effects of extended time on board, as well as complications with repatriation and the financial concerns of the unexpectedly unemployed. The well-being of seafarers during on-board COVID-19 outbreaks was evaluated with the General Health Questionnaire-12, where $60 \%$ of the sample had mean Likert-scores below 15 (i.e. "No problems"), whereas $40 \%$ had scores from 15 to 23 (i.e. initial problems). In response to other items, half of the seafarers did not feel safe performing their jobs and $60 \%$ did not think that every precaution had been taken to ensure their health at work due to the pandemic. Another $30 \%$ suffered from insomnia to the extent of becoming concerned, while $26 \%$ reported being unhappy and depressed during their latest tour of duty [23]. In response, a combination of person-focused and organization-focused prevention approaches has been advocated as the most promising for alleviating job stress in the workplace at sea (ISWAN) [24].

Without the possibility for crew changes employers have planned to extend crew contracts for one to several months. In some cases, due to COVID-related restrictions, seafarers' on-board access to medical staff has been denied by custom authorities. In February 2020, a platform for psychological phone consultations for seafarers at sea and ashore was created in France, one with assessing shock and/or acute stress as its major objective. The long-term goal to prevent PTSD among seafarers following potentially traumatic events. In early November, we performed 142 consultations with 32 seafarers from France, whose reasons for consultation were COVID-19's impact ( $n=11$ officers, $n=3$ crew members) and PTSD ( $n=10$ officers, $n=4$ crew members). We also phoned social relations of 3 seafarers, 2 retired seafarers, 2 foreign crew members and all crew members on the 3 ships about the impact of COVID- 19 and on-board accidents. Interviews revealed the importance of the feeling of isolation among seafarers, both physical and societal, and the remoteness of healthcare services. During on-board missions, seafarers suggested that they had adopted strategic defences (e.g. dissociation and structural dissociation) and collective defence strategies in the crew. Many had been undermined by fatigue, contradictory or piecemeal information on landing possibilities, the overloading of their psychological capacities for adaptation and eventually ex- haustion. The loss of those mental health resources can cause severe anxiety or suicidal crises with clinical signs of depersonalisation or paranoid disorder. At the same time, clinical signs are not comparable to usual psychiatric symptoms in acute paranoid disorder. In the case of seafarers, such conditions can be interpreted as prior dissociation with signs of a suicidal crisis - that is, an attempt to face an all-too-violent reality. Furthermore, the management and follow-up of on-board seafarers' health and well-being have specific impacts by encouraging a departure from isolation and the feeling of societal indifference, as well as an ability to re-associate their functional identities as seafarers with their personal identities. Seafarers who called the post-crisis health resource centre described symptoms of severe PTSD and the lack of all capacity to return to work on board. They recounted concrete experiences of potential death in isolated environments during the COVID-19 pandemic, when the crew did not get full compensation, and everyone was preoccupied with personal concerns and efforts to stay safe. Although the insurance system clearly needs to become more easily accessible to all seafarers, some other recommendations were made clear by the initial experiment. For one, seafarers' mental health requires care during on-board missions but also in port and between missions. For another, the societal relations of seafarers constitute a fundamental axis of health prevention, as the COVID-19 pandemic has highlighted. Thus, there is a need to focus not only on PTSD but also on all forms of psychological disorders.

The IMO has established the Seafarer Crisis Action Team (SCAT) to help to resolve individual cases, often by working alongside other organizations such as the International Labour Organization (ILO), the International Transport Workers' Federation (ITF) and the International Chamber of Shipping (ICS) [25]. Since the beginning of the COVID-19 pandemic, that dedicated team has worked around the clock to contact representatives from national governments, Non-Governmental Organizations (NGOs), trade unions and relevant associations and to orient seafarers towards the most suitable organizations and solutions. Seafarers and their relatives can contact the SCAT via email at info@imo.org.

\section{CONCLUSIONS}

To prevent mental health disorders among seafarers, all characteristics of organizations at sea, at port and in different types of vessels should be included in prevention programmes, and more research should be conducted on factors of boredom and stress among seafarers and fishermen. We fear long-term psychological and social effects on seafarers of COVID-19 pandemic. In first part, psychological disorders like depression, anxiety and increased rate of suicide will appeared. In a second part, with anxiety, social pressure from family and financial difficulties, we could 
hypothesize that numerous seafarers refuse to go back on board vessels and leave the maritime transport. Increasing access and information on health and psychologist consultations in face to face or by videoconference is imperative. Capacities of crew changing, help from health services and foreign offices are also needed. Discussion between international organizations, shipping and workers institutions to build short-term and long-term prevention actions could surely be benefit for seafarers.

\section{ACKNOWLEDGEMENTS}

Acknowledgements to Annette Leclerc for her relevant advices and time spending in reviewing this article and Mr Delalande $\mathrm{J}$ for language editing.

\section{REFERENCES}

1. Oldenburg M, Jensen $\mathrm{HJ}$, Lucas $\mathrm{D}$, et al. Stress and strain among seafarers related to the occupational groups. Int J Environ Res Public Health. 2019; 16(7): E1153, doi: 10.3390/ijerph16071153, indexed in Pubmed: 30935082

2. Oldenburg M, Jensen HJ, Latza U, et al. Seafaring stressors aboard merchant and passenger ships. Int J Public Health. 2009; 54(2): 96-105, doi: 10.1007/s00038-009-7067-z, indexed in Pubmed: 19288290 .

3. Allen $P$, Wadsworth $E$, Smith A. Seafarers' fatigue: a review of the recent literature. Int Marit Health. 2008; 59(1-4): 81-92, indexed in Pubmed: 19227741.

4. Jeżewska M, Leszczyńska I, Jaremin B. Work-related stress at sea self estimation by maritime students and officers. Int Marit Health. 2006; 57(1-4): 66-75, indexed in Pubmed: 17312695.

5. Lodde B, Jegaden D, Lucas D, et al. Stress in seamen and non seamen employed by the same company. Int Marit Health. 2008; 59(1-4): 53-60, indexed in Pubmed: 19227738.

6. Hill AB, Perkins RE. Towards a model of boredom. Br J Psychol. 1985; 76 ( Pt 2): 235-240, doi: 10.1111/j.2044-8295.1985.tb01947.x, indexed in Pubmed: 4027489.

7. Casner SM, Schooler JW. Thoughts in flight: automation use and pilots' task-related and task-unrelated thought. Hum Factors. 2014; 56(3): 433-442, doi: 10.1177/0018720813501550, indexed in Pubmed: 24930166.

8. Cummings ML, Gao F, Thornburg KM. Boredom in the workplace: a new look at an old problem. Hum Factors. 2016; 58(2): 279-300, doi: 10.1177/0018720815609503, indexed in Pubmed: 26490443.

9. Fisherl C. Boredom at work: a neglected concept. Human Relations. 2016; 46(3): 395-417, doi: 10.1177/001872679304600305.
10. Kass S, Vodanovich S, Callender A. State-trait boredom: relationship to absenteeism, tenure and job satisfaction. J Business Psychology. 2001; 16(2): 317-327.

11. Todman M. The dimensions of state boredom frequency, duration, unpleasantness consequences and causal attributions. Edu Res Int. 2013; 1(1): 32-40.

12. Vodanovich SJ, Wallace JC, Kass SJ. A confirmatory approach to the factor structure of the Boredom Proneness Scale: evidence for a two-factor short form. J Pers Assess. 2005; 85(3): 295-303, doi: 10.1207/s15327752jpa8503_05, indexed in Pubmed: 16318568.

13. Jegaden $D$, Menaheze M, Lucas D, et al. Don't forget about seafarer's boredom. Int Marit Health. 2019; 70(2): 82-87, doi: 10.5603/ IMH.2019.0013, indexed in Pubmed: 31237666.

14. Oldenburg M, Jensen HJ. Needs and possibilities for ship's crews at high seas to communicate with their home. Int J Occup Med Environ Health. 2019; 32(6): 805-815, doi: 10.13075/ijomeh.1896.01436, indexed in Pubmed: 31663520.

15. An Ji, Liu Y, Sun Y, et al. Impact of work-family conflict, job stress and job satisfaction on seafarer performance. Int J Environ Res Public Health. 2020; 17(7), doi: 10.3390/ijerph17072191, indexed in Pubmed: 32218272.

16. Siegrist J. Adverse health effects of high-effort/low-reward conditions. J Occ Health Psychology. 1996; 1(1): 27-41, doi: 10.1037/1076-8998.1.1.27.

17. Mikulas W, Vodanovich J. The essence of boredom. Psychological Record. 1993; 43: 3-12.

18. Saunders K, Rogovin T, Eckhoff M. The effects of boredom and depression on substance use and problematic internet use. J Addict Res Ther. 2012; 3: 4.

19. van Hooff MLM, van Hooft EAJ. Boredom at work: proximal and distal consequences of affective work-related boredom. J Occup Health Psychol. 2014; 19(3): 348-359, doi: 10.1037/a0036821, indexed in Pubmed: 24885686.

20. Iversen RTB. The mental health of seafarers. Int Marit Health. 2012; 63(2): 78-89, indexed in Pubmed: 22972547.

21. Jensen $\mathrm{HJ}$, Oldenburg M. Potentially traumatic experiences of seafarers. J Occup Med Toxicol. 2019; 14: 17, doi: 10.1186/s12995019-0238-9, indexed in Pubmed: 31164911.

22. https://www.imo.org/en/MediaCentre/HotTopics/Pages/Support-for-seafarers-during-COVID-19.aspx.

23. Pesel G, Canals ML, Sandrin M, et al. Wellbeing of a selection of seafarers in Eastern Adriatic Sea during the COVID-19 pandemic 2020. Int Marit Health. 2020; 71(3): 184-190, doi: 10.5603/ IMH.2020.0033, indexed in Pubmed: 33001430.

24. https://www.seafarerswelfare.org/news/2020/world-mental-health-day-mental-health-for-all-seafarers.

25. http://www.oecd.org/greengrowth/greening-transport/41763672.pdf. 